\title{
A novel sequence-specific RNA quantification method using nicking endonuclease, dual-labeled fluorescent DNA probe, and conformation-interchangeable oligo-DNA
}

\author{
KAZUFUMI HOSODA, ${ }^{1}$ TOMOAKI MATSUURA, ${ }^{2}$ HIROSHI KITA, ${ }^{3}$ NORIKAZU ICHIHASHI, ${ }^{3}$ \\ KOJI TSUKADA, ${ }^{4}$ ITARU URABE, ${ }^{4}$ and TETSUYA YOMO ${ }^{1,2,3}$ \\ ${ }^{1}$ Graduate School of Frontier Biosciences, Osaka University, Osaka 565-0871, Japan \\ ${ }^{2}$ Department of Bioinformatics Engineering, Graduate School of Information Science and Technology, Osaka University, Osaka 565-0871, Japan \\ ${ }^{3}$ Complex Systems Biology Project, Exploratory Research for Advanced Technology (ERATO), Japan Science and Technology Agency (JST), \\ Saitama 332-0012, Japan \\ ${ }^{4}$ Department of Biotechnology, Graduate School of Engineering, Osaka University, Osaka 565-0871, Japan
}

\begin{abstract}
We have developed a novel, single-step, isothermal, signal-amplified, and sequence-specific RNA quantification method (Lassay). The L-assay consists of nicking endonuclease, a dual-labeled fluorescent DNA probe (DL-probe), and conformationinterchangeable oligo-DNA (L-DNA). This signal-amplified assay can quantify target RNA concentration in a sequence-specific manner with a coefficient of variation $(\mathrm{Cv})$ of $5 \%$ and a lower limit of detection of $0.1 \mathrm{nM}$. Moreover, this assay allows quantification of target RNA even in the presence of a several thousandfold excess by weight of cellular RNA. In addition, this assay can be used to measure the changes in RNA concentration in real-time and to quantify short RNAs ( $<30$ nucleotides). The L-assay requires only incubation under isothermal conditions, is inexpensive, and is expected to be useful for basic research requiring high-accuracy, easy-to-use RNA quantification, and real-time quantification.
\end{abstract}

Keywords: nicking endonuclease; dual-labeled fluorescent DNA probe; sequence-specific quantification; RNA quantification; conformation-interchangeable oligo-DNA; real-time quantification

\section{INTRODUCTION}

The specificity of nucleic acid hybridization is a fundamental requirement for identification of target RNA sequences. A number of sequence-specific RNA quantification methods based on hybridization have been developed for various purposes (Collins et al. 1997; Eis et al. 2001; Tanke et al. 2005; Wheeler et al. 2005; Marras et al. 2006; Mothershed and Whitney 2006), such as to study the function of various RNAs (Hannon 2002; Berezikov et al. 2006) and for the detection of pathogens (Mahony et al. 2001; Yam et al. 2004). Northern blotting, quantitative reverse transcription polymerase chain reaction (Q-RTPCR), and molecular

Reprint requests to: Tetsuya Yomo, Department of Bioinformatics Engineering, Graduate School of Information Science and Technology, Osaka University, 2-1 Yamadaoka, Suita, Osaka 565-0871, Japan; e-mail: yomo@ist.osaka-u.ac.jp; fax: 81-6-6879-7433.

Article published online ahead of print. Article and publication date are at http://www.rnajournal.org/cgi/doi/10.1261/rna.761708. beacons are representative in vitro RNA quantification methods (Tyagi and Kramer 1996; Bird 1998; Sambrook and Russell 2001). By Northern blotting, it is possible not only to quantify the target RNA but also to determine its length, although this method requires many handling procedures, making it time-consuming and subject to the risk of operational errors resulting in low accuracy. QRTPCR can detect even a single molecule of the target RNA and has a very wide dynamic range, although it requires a thermal cycler for signal amplification, precise temperature control for accurate quantification, and refinements for detection of short RNAs (Chen et al. 2005). Molecular beacons are usually used as probes for Q-RTPCR or for other signal-amplified quantification methods (Marras et al. 2006). In addition, the molecular beacon itself has been used for sequence-specific quantification in real-time through hybridization to a specific sequence, although the sensitivity of this method is expected to be low because it is not a signal-amplified method. Thus, all available methods 
have both advantages and disadvantages, and development of new methods that complement the current strategies, particularly with regard to accuracy and convenience of quantification, are expected to provide new insight in basic studies and applied science.

We have developed a novel, single-step, isothermal, signal-amplified, and sequence-specific RNA quantification method (L-assay). This assay is composed of nicking endonuclease (Xu et al. 2001), a dual-labeled fluorescent DNA probe (DL-probe) (Johansson et al. 2002), and a conformation-interchangeable oligo-DNA (L-DNA), and requires only that these components be mixed and placed under isothermal conditions for 10-30 $\mathrm{min}$. In the L-assay, the presence of the target RNA sequence will result in an increase in fluorescence intensity. We found that the rate of fluorescence increase was proportional to the target RNA concentration, even in the presence of a several thousandfold excess by weight of nontarget RNA, indicating that the L-assay can quantify the target RNA in a sequence-specific manner. The coefficient of variation $(\mathrm{Cv})$, which is the ratio of standard deviation to mean of quantification, ranged from $4.0 \%$ to $6.7 \%$. The lower limit of detection was $0.1 \mathrm{nM}$, and we discuss the potential for further increasing the sensitivity of this method. Moreover, we found that the L-assay is relatively insensitive to the design of the DLprobe and L-DNA sequences, indicating the robustness of the assay. Furthermore, we demonstrated real-time quantification of RNA degradation by RNase A using L-assay. The L-assay is an easy-to-use method for RNA quantification or detection and for real-time RNA quantification (Marras et al. 2004; Rondelez et al. 2005), and is particularly useful for studies requiring a high degree of accuracy and/or quantification of short RNAs.

\section{RESULTS}

\section{Scheme of the L-assay}

The L-assay is composed of nicking endonuclease, DLprobe, and L-DNA (Fig. 1). Nicking endonuclease is an enzyme that binds to its asymmetrical recognition sequence in double-stranded DNA and nicks only one specific strand of the duplex (Xu et al. 2001). The DL-probe is a short (1115 nucleotides [nt]) oligo-DNA, which carries the recognition sequence and cleavage site for the nicking endonuclease $N b . B b v C$ I (Heiter et al. 2005), and is labeled with the fluorescent dye 6-carboxyfluorescein (6-FAM) and its quencher Black Hole Quencher 1 (BHQ1) at the $5^{\prime}$ - and $3^{\prime}$-ends, respectively (Johansson et al. 2002). Therefore, a fluorescence signal appears only when the DL-probe is cleaved by $N b . B b v C$ I. The L-DNA is a mediator oligo-DNA (Fig. 1A), which changes its conformation from the hairpin form to the open form on hybridization with the target RNA sequence. The L-DNA has sequences complementary to both the target sequence and DL-probe (underlined black
A

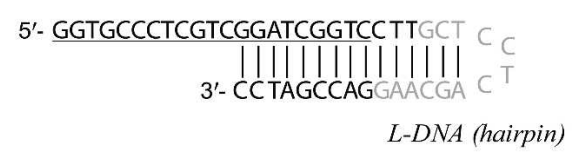

B

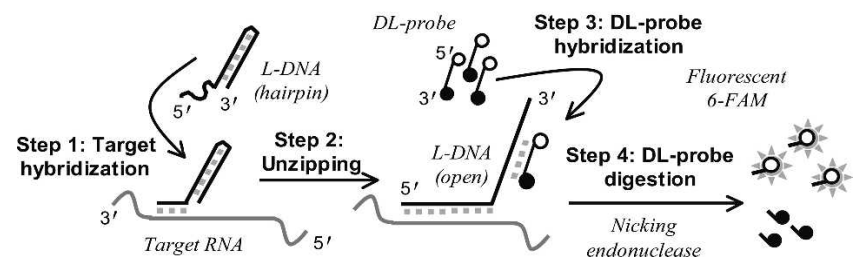

FIGURE 1. Scheme of the L-assay. (A) Sequence and predicted secondary structure of L-DNA (L46). To maintain the hairpin structure, L-DNA was designed carrying (from the $5^{\prime}$-end) the complement of the target sequence (underlined black characters), the identical sequence to the 3 -nt $5^{\prime}$-end of the DL-probe $\left(5^{\prime}\right.$-CTT- 3 '), the complement of the DL-probe sequence (gray characters), and the identical sequence to the $5^{\prime}$ part of the target sequence $\left(5^{\prime}\right.$ GACCGATCC- $\left.3^{\prime}\right)$. (B) Four steps of the reaction in the L-assay. (Step 1) Hybridization between L-DNA and target sequence. (Step 2) Unzipping of the L-DNA by double-strand formation with the target sequence. (Step 3) Hybridization between L-DNA and DL-probe. (Step 4) Cleavage of the DL-probe by $\mathrm{Nb} \cdot \mathrm{BbvC} \mathrm{I}$, and generation of the fluorescent signal. Steps 3 and 4 were repeated.

and gray characters in Fig. 1A, respectively). The hairpin form L-DNA can hybridize easily with the target sequence because the $5^{\prime}$-end of L-DNA is single stranded, while it is difficult to hybridize to the DL-probe. Hybridization of LDNA with the target sequence unzips the double-stranded structure of the hairpin, causing the L-DNA to adopt the open form (Fig. 1B, Steps 1,2). This is because L-DNA is energetically more stable when adopting a double-stranded structure with the target sequence than the hairpin form. In the open form, the L-DNA sequence complementary to the DL-probe is accessible, and it therefore becomes double stranded with the DL-probe (Fig. 1B, Step 3). The doublestranded DL-probe is a substrate of $N b . B b v C \mathrm{I}$, and fluorescence is produced upon cleavage of the DL-probe (Fig. 1B, Step 4). Following cleavage of the DL-probe, it dissociates from the L-DNA because the cleaved DL-probe is too short to maintain the double-stranded conformation and the next uncleaved DL-probe hybridizes to the L-DNA. In this way, fluorescence is produced continuously. The rate of the increase in fluorescence is expected to be proportional to the target RNA concentration, until the concentration of target RNA becomes greater than that of L-DNA. Therefore, the target RNA concentration can be quantified by determination of the rate of increase in fluorescence.

\section{Target RNA-dependent fluorescence increase}

The experimental procedure of the L-assay is very simple. The unknown sample (target) is added to the quantification 
mixture containing the DL-probe, L-DNA, and nicking endonuclease, and incubated under isothermal conditions. Figure $2 \mathrm{~A}$ shows the time courses of the increases in fluorescence at $37^{\circ} \mathrm{C}$ obtained with this assay using $500 \mathrm{nM}$ DL-probe (NBFB_13) and $10 \mathrm{nM}$ L-DNA (L46) in the presence of $4 \mathrm{nM}$ Qb3716(-)RNA $(\bullet)$, the target RNA, or without the target RNA $(O)$. All sequences of oligo-DNA and RNA, i.e., the DL-probe, L-DNA, and targets, used in this study are shown in Table 1. Qb3716(-)RNA contained the target sequence for L46, and thus the fluorescence increase in the presence of Qb3716(-)RNA (๑) was much greater than that without RNA $(O)$.

Figure $2 \mathrm{~B}$ shows the slopes of the time course of fluorescence increase using L46 (Fig. 2B, white bars) or L1HF (Fig. 2B, gray bars) as L-DNA in the presence of Qb3716(-) RNA and/or HF2694RNA, or without any RNA. Figure 2B also shows the slope without L-DNA (Fig. 2B, black bar). HF2694RNA contained the target sequence for L1HF, while Qb3716(-)RNA contained that for L46. In both cases, using L46 and L1HF, we found that the slopes in the presence of the correct target sequence were much greater than those without the target sequence. Moreover, the signal was not affected by the presence of a 25 -fold higher molar concentration of nontarget sequences. These results indicated that the sequence-specific detection using the reaction pathway depicted in Figure 1B is operative. It should also

A
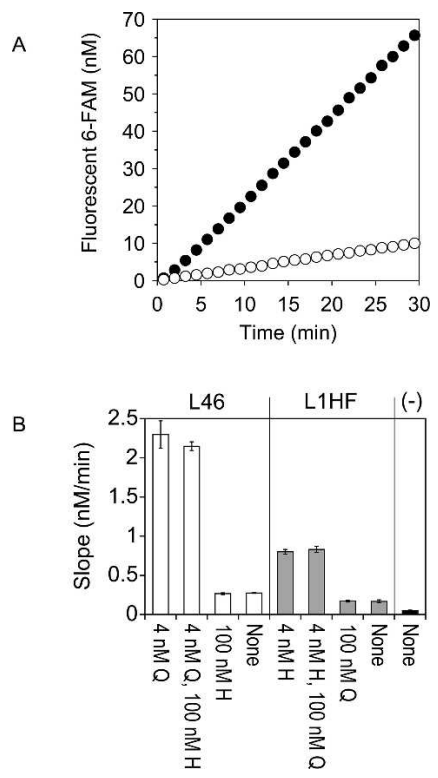

FIGURE 2. Target RNA-dependent fluorescence increase. (A) The time course of the fluorescence increase in the L-assay using $10 \mathrm{nM}$ L46 as L-DNA in the presence of $4 \mathrm{nM}$ target RNA (Qb3716(-)RNA) $(-)$ or without RNA $(O)$. (B) The slopes of the time course of fluorescence increase using $10 \mathrm{nM}$ L46 (white bars) or $10 \mathrm{nM} \mathrm{L1HF}$ (gray bars) as L-DNA or without L-DNA (black bar), in the presence of Qb3716(-)RNA and/or HF2694RNA (abbreviated as Q and H, respectively) or without RNA (None). The L-DNA and the concentrations of RNA used are indicated at the top and bottom of the figure, respectively. be noted that the concentration of fluorescent 6-FAM (Fig. 2A, vertical axis), corresponding to the concentration of cleaved DL-probe, increased far beyond the concentrations of both the target RNA ( $4 \mathrm{nM})$ and L-DNA (10 nM), confirming the turnover reaction in Steps 3 and 4 in Figure 1B. While almost no signal was observed without L-DNA (Fig. 2B, black bar, "None"), a small signal was observed with L-DNA even without any target RNA (Fig. 2B, white and gray bars, "None"). The small signal was directly proportional to the L-DNA concentration (data not shown), indicating that a small fraction of the L-DNA was likely to be in the open form without hybridization with the target sequence, and this was the background of the L-assay.

\section{Standard curves}

Figure 3 shows the correlation between the slope of fluorescence increase and the target RNA concentration using $10 \mathrm{nM} \mathrm{L46} \mathrm{(Fig.} \mathrm{3A),} 100 \mathrm{nM}$ L46 (Fig. 3B), or $10 \mathrm{nM} \mathrm{L2GFP} \mathrm{(Fig.} \mathrm{3C)} \mathrm{as} \mathrm{L-DNA.} \mathrm{Qb3716(-)RNA} \mathrm{and}$ GFP5C_RNA were used as target RNAs for L46 (Fig. 3A,B) and L2GFP (Fig. 3C), respectively. GFP5C_RNA is $845 \mathrm{nt}$ in length, which is much longer than Qb3716(-)RNA (30 nt, Table 1). Two individual points at each target RNA concentration ( $O$ and $\mathbf{\Delta}$ ) show the results of duplicate reactions. In all cases, there was a range of target RNA concentration where the slope of fluorescence increase was proportional to the target RNA concentration, indicating that the L-assay can be used as a quantification method. The solid lines in Figure 3, A, B, and C indicate the linear regression of the data from 0 to $8 \mathrm{nM}, 0$ to $64 \mathrm{nM}$, and 0 to $16 \mathrm{nM}$, respectively, which gave a slope and intercept of $0.45 / \mathrm{min}$ and $0.34 \mathrm{nM} / \mathrm{min}\left(R^{2}=0.996\right), 0.39 / \mathrm{min}$ and $2.8 \mathrm{nM} / \mathrm{min}\left(R^{2}=0.994\right)$, and $0.014 / \mathrm{min}$ and $0.18 \mathrm{nM} / \mathrm{min}$ $\left(R^{2}=0.981\right)$, respectively. The coefficient of variation $(\mathrm{Cv})$, which is the ratio of standard deviation to the mean of quantification, between the duplicates was independent of the target RNA concentration and showed an average of $4.0 \%$.

In Figure 3, A and B, the slope no longer increased when the concentration of the target RNA exceeded that of LDNA, suggesting that the L-DNA was saturated with target RNA. On the other hand, in Figure 3C, the slope increased even when the target RNA concentration was much greater than the L-DNA concentration $(10 \mathrm{nM})$, and the slope of the fitted linear line $(0.014 / \mathrm{min})$ was notably less than those in Figure 3, A and B (0.45 and 0.39/min, respectively). No such observations were made in the case of all short target RNAs or DNAs tested (data not shown), and were attributed to the fact that the affinity between the L-DNA and the target RNA was low and not all L-DNA hybridized to the target sequence, even at higher target RNA concentrations. In such cases, the L-assay reaction can be explained by a Michaelis-Menten-like mechanism (Fersht 1999); indeed, the data showed a good fit to the Michaelis-Menten equation 
TABLE 1. Sequences of the oligo-DNA and RNA used in this study

DL-probe
NBFB_11
NBFB_13
NBFB_15
NBFB_B

L-DNA

L46_5'-4

L46_5' -3

L46_5'-2

L46_5' -1

L46

L46_5'+2

L46_5'+4

L46_5'-4_3'-2

L46_5' $-2 \_3^{\prime}+2$

L46_3'+2

L46_5' $+2 \_3^{\prime}+4$

L47

L_165

L_T

L_T_B

L1HF

L2GFP

Target RNA

Qb3716(-)RNA

HF2694RNA

GFP5C_RNA

\section{Target DNA}

Qb3716(-)DNA

$\mathrm{FH}(-)$ 160DNA

MT(-)160DNA
(6-FAM) 5'-TTGCTGAGGAG-3' (BHQ1)

(6-FAM) 5'-CTTGCTGAGGAGC-3' (BHQ1)

(6-FAM) 5'-GCTTGCTGAGGAGCA-3' (BHQ1)

(6-FAM)5'-CTTGCTGAGGCAG-3'(BHQ1)

5'-CCCTCGTCGGATCGGTCCTTGCTCCTCAGCAAGGACCGATCC-3'

5'-GCCCTCGTCGGATCGGTCCTTGCTCCTCAGCAAGGACCGATCC-3'

5'-TGCCCTCGTCGGATCGGTCCTTGCTCCTCAGCAAGGACCGATCC-3'

5'-GTGCCCTCGTCGGATCGGTCCTTGCTCCTCAGCAAGGACCGATCC-3'

5'-GGTGCCCTCGTCGGATCGGTCCTTGCTCCTCAGCAAGGACCGATCC-3'

5'-ATGGTGCCCTCGTCGGATCGGTCCTTGCTCCTCAGCAAGGACCGATCC-3'

5'-TGATGGTGCCCTCGTCGGATCGGTCCTTGCTCCTCAGCAAGGACCGATCC-3'

5'-CCCTCGTCGGATCGGTCCTTGCTCCTCAGCAAGGACCGAT-3'

5'-TGCCCTCGTCGGATCGGTCCTTGCTCCTCAGCAAGGACCGATCCGA-3'

5'-GGTGCCCTCGTCGGATCGGTCCTTGCTCCTCAGCAAGGACCGATCCGA-3'

5'-ATGGTGCCCTCGTCGGATCGGTCCTTGCTCCTCAGCAAGGACCGATCCGACG-3'

5'-GGTGCCCTCGTCGGATCGGTCCTTGCTGCCTCAGCAAGGACCGATCC-3'

5'-TGGGGCCAGATCTCGAGGCCTTGCTCCTCAGCAAGGCCTCGAGA-3'

5'-TTTTTGTTTTTTTTTAGATCTCGAGGCTTGCTCCTCAGCAAGCCTCGAGAT-3'

5'-TTTTTGTTTTTTTTTAGATCTCGAGGCTTGCTGCCTCAGCAAGCCTCGAGAT-3'

5'-ACUUCUCAUCUUCUAGUUGGUCTTGCTCCTCAGCAAGACCAACUAG-3'

5'-GTTGTACTCGAGTTTGTGTCCTTGCTCCTCAGCAAGGACACAAAC-3'

5'-GAUUAGGACCGAUCCGACGAGGGCACCAUC-3'

5'-GACCAACUAGAAGAUGAGAAGU-3'

$845 \mathrm{nt}^{\mathrm{a}}$

5'-GATTAGGACCGATCCGACGAGGGCACCATC-3'

5'-TAGCAGGCCTCGAGATCTGGCCCCAGAGGC-3'

5'-TAGCAGGCCTCGAGATCTAAAAAAAACAAAAAAAAAAAAAATGATCT-3'

${ }^{a}$ Sequence information available at http://www-symbio.ist.osaka-u.ac.jp/Supplemental.pdf.

(Fig. 3C, dotted line). Such low affinity should appear when the target sequence was not always accessible due to the secondary structure, which is likely to be the case when the RNA becomes longer. Nevertheless, it should be noted that the target RNA concentration could be quantified using a standard curve fitted by the Michaelis-Menten equation, while its accuracy may become lower than linear regression.

We determined upper detection limit $(U L)$, lower detection limit $(L L)$, and the dynamic range, which is the ratio of $U L$ to $L L$, of the $\mathrm{L}$-assay. The $U L$ of the $\mathrm{L}$-assay was almost the same as the L-DNA concentration when quantifying short RNAs ( -47 bases) such as Qb3716(-)RNA and HF2694RNA (Fig. 3A,B), whereas $U L$ was about $100 \mathrm{nM}-10$-fold greater than the L-DNA concentrationfor GFP5C_RNA with a length of 845 bases (Fig. 3C). UL of GFP5C_RNA was estimated as the concentration of RNA that gave half of the maximum slope determined by nonlinear regression (Michaelis-Menten equation). The lower detection limit $(L L)$ can be defined as the RNA concentration, the signal of which is $\beta+3 \cdot \sigma_{B}$, where $\beta$ is the mean value of the blank signal and $\sigma_{B}$ is the standard deviation of the blank signal (i.e., $\left.\sigma_{\mathrm{B}}=\mathrm{Cv} \cdot \beta\right)($ MacDougall et al. 1980). The value of $\beta$ is equivalent to the intercept of the linear standard curve, and $L L$ can be determined as $3 \cdot \mathrm{Cv} \cdot \beta / \alpha$ by solving the equation $\beta+3 \cdot \mathrm{Cv} \cdot \beta=\alpha \cdot L L+\beta$, where $\alpha$ is the slope of the linear standard curve. In this way, $L L$ in Figure $3, \mathrm{~A}, \mathrm{~B}$, and $\mathrm{C}$ were determined to be $0.090 \mathrm{nM}, 0.86 \mathrm{nM}$, and $1.4 \mathrm{nM}$, respectively, using the value of $\mathrm{Cv}=4.0 \%$. The dynamic ranges $(U L / L L)$ in Figure $3, \mathrm{~A}, \mathrm{~B}$, and $\mathrm{C}$ were two orders of magnitude. It is worth noting that the quantification range of the assay (i.e., $L L$ to $U L)$ can be altered easily as both $L L$ and $U L$ can be controlled by the L-DNA concentration.

\section{Influence of the DL-probe and L-DNA sequences}

We investigated the influence of the DL-probe and L-DNA sequences on L-assay performance. The slopes (nanomolar/ $\mathrm{min}$ ) of the fluorescence increase obtained using various DL-probes and L-DNAs (10 nM) for detecting $4 \mathrm{nM}$ target RNA or DNA (AS: Analyte Signal) with a variety of sequences, or without target sequence (BS: Blank Signal) are summarized in Table 2. The values of AS and BS listed in Table 2 are the means of two individual experiments, 
A

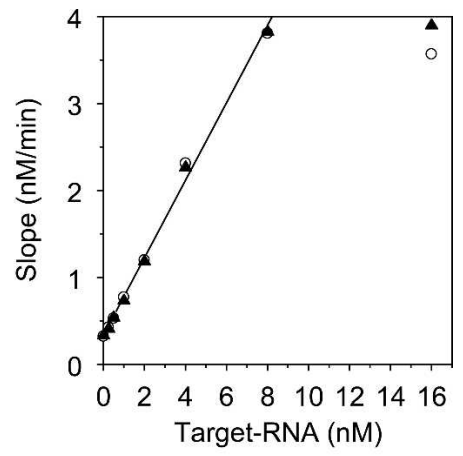

B

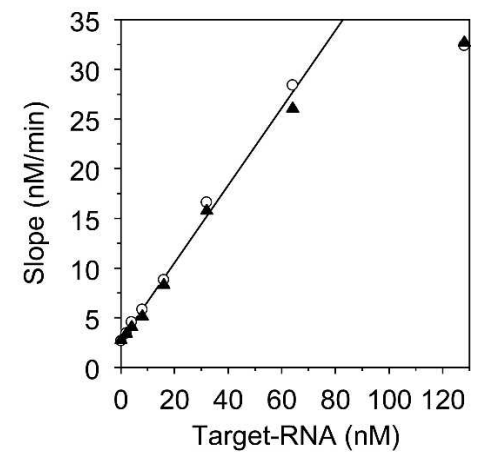

C

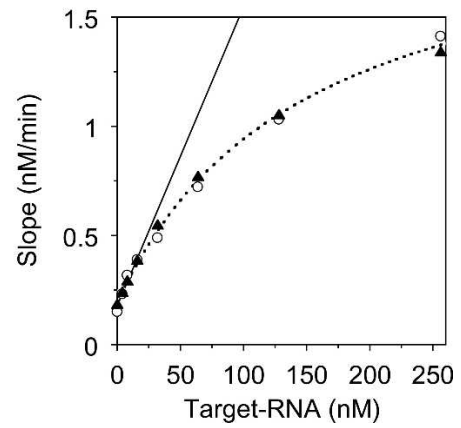

FIGURE 3. Correlation between the slope of the fluorescence increase and target RNA concentration. Results obtained using the L-assay with $10 \mathrm{nM} \mathrm{L46}(A), 100 \mathrm{nM}$ L46 $(B)$, and $10 \mathrm{nM} \mathrm{L2GFP}(C)$. Two points at each target concentration $(\bigcirc$ and $\mathbf{A})$ show the results of duplicate reactions. The solid lines represent the linear regression of the data and the fitting results are described in the text. The dotted line in $C$ is the nonlinear regression using the Michaelis-Menten equation Slope $=1.9 \cdot T /(150+T)+0.19$, where $T$ is Target-RNA $(\mathrm{nM})$.

and $\mathrm{Cv}$ between the two showed an average value of $6.7 \%$. We also listed $L L$ (nanomolars) determined as $3 \cdot \mathrm{Cv} \cdot \beta / \alpha$, where $\mathrm{Cv}=6.7 \%, \beta=\mathrm{BS}$, and $\alpha=(\mathrm{AS}-\mathrm{BS}) / 4(\beta$ and $\alpha$ are the intercept and the slope of the standard curve, respectively, deduced from the values of AS and BS). We found that $L L$ was significantly less than the L-DNA concentration $(10 \mathrm{nM})$ under all conditions tested. As the L-DNA concentration defines the lowest value of $U L$, there is a certain quantification range under all conditions tested. More precisely, the assay system could quantify the target concentration even when the length of L-DNA was varied by at most $6 \mathrm{nt}$ (Table 2, Conditions 1-11), when the length of the DL-probe was shortened or lengthened by $2 \mathrm{nt}$ (Table 2, Conditions 13,14, respectively), when the combination of target sequence and L-DNA was varied (Table 2, Conditions 16-20), when the length of the loop structure of the L-DNA (5'-CCTC-3' in gray characters in Fig. 1A) was varied from $4 \mathrm{nt}$ to $3 \mathrm{nt}$ (Table 2, Conditions 15,18), and even using DNA as a target sequence (Table 2, Conditions 12,16-18). These results indicate the robustness of this assay system on the design of the L-DNA and DL-probe sequences. As there were no obvious correlations between the length of L-DNA or DL-probe and the obtained AS and BS, the exact sequence may have a stronger influence on the performance of the assay than minor changes in the length.

NBFB_13 is the DL-probe used most in this study, which in principle can be used as a common DL-probe for all target sequences as long as the target RNA or DNA does not contain the same or a very closely related sequence to NBFB_13 or its complement. In such cases, however, it is also possible to use another set of nicking endonuclease and DL-probe. L-DNA should be designed as follows (in order from the $5^{\prime}$-end): the complement of the target sequence (about $20 \mathrm{nt}$; we used 18-30 nt) (see Fig. 1A, underlined characters; Tables 1,2), the same sequence as 3 nt $5^{\prime}$-end of the DL-probe (Fig. 1A, 5'-CTT-3'), the complement of the DL-probe sequence (Fig. 1A, gray characters), and the same sequence as the $5^{\prime}$ part of the target sequence (about $10 \mathrm{nt}$; we tested 7-13 nt) (see Fig. 1A, 5'-GACCGATCC-3'; Tables $1,2)$. Our results suggested that the L-assay should work for most target sequences by adhering to the above outline.

\section{Demonstration of quantification in the presence of cellular RNA}

We examined whether a specific RNA can be quantified even in the presence of large amounts of cellular RNA from yeast. Figure 4 shows the results of the influence of total RNA (from yeast) on both AS (slope of the fluorescence increase with $4 \mathrm{nM}(0.04 \mathrm{ng} / \mu \mathrm{L})$ Qb3716(-)RNA as target RNA, white bar) and BS (that without target sequence, gray bar) using L46 as L-DNA. We found that cellular RNA did not increase BS, and AS was sufficiently higher than BS even in the presence of a 2500 -fold excess by weight (100/ 0.04) of cellular RNA. As the presence of cellular RNA reduced AS, presumably due to competitive inhibition of nicking endonuclease activity by nonspecific binding to cellular RNA (Langowski et al. 1980), the standard curve must be plotted using the data obtained in the presence of the same concentration of unrelated RNA.

\section{Demonstration of real-time quantification of RNA degradation by RNase A}

One of the most important features of the L-assay is its ability to quantify the RNA concentration in real-time. 
TABLE 2. Results using various DL-probes, L-DNA, and targets

\begin{tabular}{|c|c|c|c|c|c|c|}
\hline Condition & DL-probe & L-DNA & Target & AS (nM/min) & $\mathrm{BS}(\mathrm{nM} / \mathrm{min})$ & $L L(\mathrm{nM})$ \\
\hline 1 & NBFB_13 & L46_5'-4 & Qb3716(-)RNA & 2.2 & 0.56 & 0.28 \\
\hline 2 & NBFB_13 & L46_5'-3 & Qb3716(-)RNA & 2.1 & 0.59 & 0.31 \\
\hline 3 & NBFB_13 & L46_5'-2 & Qb3716(-)RNA & 3.1 & 2.1 & 1.7 \\
\hline 4 & NBFB_13 & L46_5'-1 & Qb3716(-)RNA & 2.3 & 0.72 & 0.36 \\
\hline 5 & NBFB_13 & L46 & Qb3716(-)RNA & 2.3 & 0.28 & 0.11 \\
\hline 6 & NBFB_13 & L46_5'+2 & Qb3716(-)RNA & 1.8 & 0.73 & 0.54 \\
\hline 7 & NBFB_13 & L46_5'+4 & Qb3716(-)RNA & 2.0 & 0.85 & 0.61 \\
\hline 8 & NBFB_13 & L46_5'-4_3'-2 & Qb3716(-)RNA & 1.7 & 0.34 & 0.20 \\
\hline 9 & NBFB_13 & L46_5'-2_3'+2 & Qb3716(-)RNA & 1.6 & 0.51 & 0.37 \\
\hline 10 & NBFB_13 & L46_3'+2 & Qb3716(-)RNA & 1.6 & 0.41 & 0.29 \\
\hline 11 & NBFB_13 & L46_5'+2_3'+4 & Qb3716(-)RNA & 2.2 & 0.60 & 0.30 \\
\hline 12 & NBFB_13 & L46 & Qb3716(-)DNA & 3.3 & 0.28 & 0.072 \\
\hline 13 & NBFB_11 & L46 & Qb3716(-)RNA & 0.70 & 0.14 & 0.20 \\
\hline 14 & NBFB_15 & L46 & Qb3716(-)RNA & 1.4 & 0.28 & 0.20 \\
\hline 15 & NBFB_B & L47 & Qb3716(-)RNA & 0.39 & 0.087 & 0.23 \\
\hline 16 & NBFB_13 & L_165 & $\mathrm{FH}(-) 160 \mathrm{DNA}$ & 3.1 & 0.56 & 0.17 \\
\hline 17 & NBFB_13 & L_T & MT(-)160DNA & 1.7 & 0.4 & 0.24 \\
\hline 18 & NBFB_B & L_T_B & MT(-)160DNA & 1.2 & 0.091 & 0.065 \\
\hline 19 & NBFB_13 & L1HF & HF2694RNA & 0.80 & 0.17 & 0.22 \\
\hline 20 & NBFB_13 & L2GFP & GFP5C_RNA & 0.24 & 0.17 & 1.97 \\
\hline
\end{tabular}

"AS" and "BS" are the slopes of fluorescence increases with $4 \mathrm{nM}$ target sequence and without target, respectively. The values shown here are the means of two individual experiments, and the average Cv of the two was $6.7 \%$.

That is, the changes in the RNA concentration during a reaction can be detected without sampling. As an example, RNA degradation by RNase A was quantified in real-time. Figure 5A shows the time courses of the increases in fluorescence using L46 as L-DNA for $4 \mathrm{nM}$ Qb3716(-)RNA as target $\mathrm{RNA}(\bullet), 4 \mathrm{nM}$ Qb3716(-)RNA with $12 \mu \mathrm{M}$ RNase A $(\bigcirc)$, and neither target sequence nor RNase A $(X)$. A reduction in the rate of fluorescence increase (slope) was observed in the presence of RNase A $(O)$. Figure $5 \mathrm{~B}$ shows the time courses of changes in the target RNA concentration determined from the slope of Figure 5A and the standard curve (Fig. 3A). A single exponential decrease in the RNA concentration with a rate of $0.18 \pm 0.01 / \mathrm{min}$ was observed. The specificity constant $\left(k_{\text {cat }} / K_{\mathrm{m}}\right.$, where $k_{\text {cat }}$ and $K_{\mathrm{m}}$ are catalytic rate constant and the Michaelis constant, respectively) can be determined as $2.5 \times 10^{2}$ $\mathrm{M}^{-1} \mathrm{~s}^{-1}$ by dividing the rate $0.18 \pm 0.01 / \mathrm{min}$ by the RNase A concentration $(12 \mu \mathrm{M})$ (Fersht 1999), because the $K_{\mathrm{m}}$ of RNase A is known to be greater than the RNase A concentration used $\left(K_{\mathrm{m}}=34-620 \mu \mathrm{M}\right)$ (delCardayre and Raines 1994). The ratio $k_{\text {cat }} / K_{\mathrm{m}}$ of RNase A is known to be strongly dependent on the substrate RNA sequence, and shows a wide range of values from $2.8 \times 10^{2}$ to $1.5 \times 10^{7}$ $\mathrm{M}^{-1} \mathrm{~s}^{-1}$ (delCardayre and Raines 1994). Our value $(2.5 \times$ $10^{2} \mathrm{M}^{-1} \mathrm{~s}^{-1}$ ) was at the low end of this range; however, it is possible that the value could be underestimated by some order of magnitude because hybridization of the target RNA with L-DNA may protect the RNA from degradation by RNase A. Nevertheless, when the target RNA is the substrate of the reaction, as in the case of RNase A, L-assay as well as other methods based on hybridization may interfere with the reaction. However, when the target RNA is the product, as in the case of RNA synthesis (Marras et al. 2004; Hosoda et al. 2007), L-assay or other hybridization-based methods should not affect the reaction, and the assay is thus likely to be able to provide quantitative real-time data.

\section{Discussion}

We have developed a novel, single-step, isothermal, signalamplified, and sequence-specific RNA quantification method (L-assay). The L-assay consists of nicking endonuclease, dual-labeled fluorescent DNA probe (DL-probe), and conformation-interchangeable oligo-DNA (L-DNA),

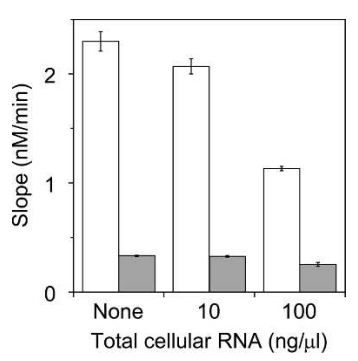

FIGURE 4. Influence of cellular RNA. The white and gray bars indicate the slopes of the fluorescence increase in the presence of cellular RNA with $4 \mathrm{nM}(0.04 \mathrm{ng} / \mu \mathrm{L})$ target RNA or without target sequence, respectively. The concentrations of cellular RNA are indicated at the bottom of the figure. 
A

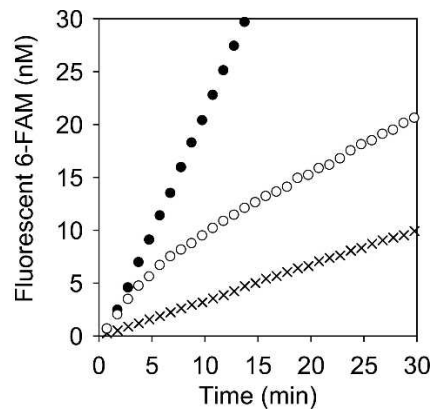

B

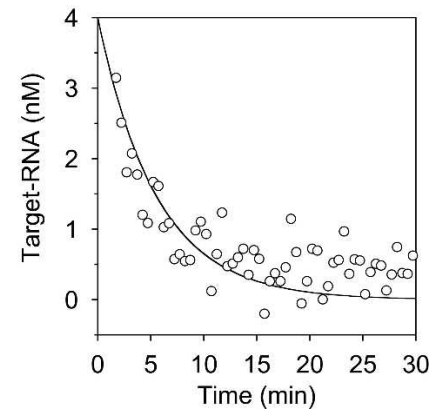

FIGURE 5. Real-time quantification of RNA degradation reaction by RNase A. (A) The time courses of fluorescence increases initiated with $4 \mathrm{nM}$ target RNA (@), $4 \mathrm{nM}$ target RNA with $12 \mu \mathrm{M}$ RNase A (O), or neither target nor RNase $A(X)$. $(B)$ The time courses of changes in the target RNA concentration determined from the slope obtained in $A$. The solid line represents the fit of the data to a single exponential, which gave a rate of $0.18 \pm 0.01 / \mathrm{min}$.

and requires simply mixing these components and placing them under isothermal conditions. The features of the Lassay are as follows: (1) $\mathrm{Cv}$ of quantification in the range of $4.0 \%-6.7 \%$ (Fig. 3; Table 2) with a lower limit of detection of $0.1 \mathrm{nM}$ (Fig. 3A); (2) detection is sequence specific and is not disturbed even in the presence of a several thousandfold excess by weight of unrelated RNA (Fig. 4); (3) quantification can be performed in real-time (Fig. 5); and (4) quantification is a signal-amplified method, i.e., the signal fluorescence increases over time. While the strategy is very simple, quantification with the L-assay results in high accuracy and signal amplification makes the method more sensitive than other sequence-specific real-time measurement methods in which the fluorescence signal is not amplified.

In addition to its accuracy, the L-assay also has a number of other useful features as follows. The L-assay can quantify short RNAs (<30 nt), such as miRNAs (Lim et al. 2003; Maroney et al. 2006). Short RNAs cannot be amplified directly by PCR, and Q-RTPCR requires refinements for short RNAs (Chen et al. 2005). Other quantification methods for short RNAs are also complicated (Allawi et al. 2004; Valoczi et al. 2004; Jonstrup et al. 2006). On the other hand, the L-assay can quantify short RNAs (see Tables 1,2 ) with a much simpler procedure (requiring only mixing and incubation) than other methods. Moreover, the cost of the L-assay is lower than for other methods using DL-probes, because not only does the L-assay not require a thermalcycler, but a single DL-probe can be used for multiple target sequences.

There is potential to further increase the sensitivity of the L-assay. The lower limit of detection of the L-assay was found to be $0.1 \mathrm{nM}$ (Fig. 3A). Both the upper and lower limits of detection are proportional to the L-DNA concentration, and thus, the quantification range can be controlled by the L-DNA concentration (Fig. 3A,B). In principle, lower RNA concentrations $(<0.1 \mathrm{nM})$ can be quantified by using lower concentrations of L-DNA $(<10$ $\mathrm{nM}$ ). However, the reaction velocity becomes very slow and the assay loses its accuracy under these conditions. Currently, the activity (catalytic rate) of $\mathrm{Nb} \cdot \mathrm{BbvC} \mathrm{I}$ is one of the rate-limiting factors in the L-assay, and thus development of a high-activity nicking endonuclease (Cherry et al. 1999; Bellamy et al. 2005; Zheng and Roberts 2007) is expected to increase the reaction rate, resulting in more sensitive quantification. Moreover, improvement of the conformation (sequence design) or chemical modification of the L-DNA may reduce BS by the L-DNA (Kean et al. 1994). Indeed, L-DNA with a 3-nt loop resulted in less BS than that with a 4-nt loop (Table 2,Conditions $15,18)$.

In conclusion, the L-assay was found to be a sequencespecific and accurate real-time RNA quantification method ( $\mathrm{Cv}$ ranged from $4.0 \%$ to $6.7 \%$ ) with a lower detection limit of $0.1 \mathrm{nM}$, and was shown to be applicable to the detection of specific sequences in cellular RNA. Further improvement of the assay with regard to its sensitivity is expected with the development of high-activity nicking endonuclease or by modification of L-DNA. The easy-touse L-assay will be useful for various purposes, such as RNA quantification of miRNA or pathogens, basic research requiring high accuracy, and sequence-specific real-time quantification.

\section{MATERIALS AND METHODS}

\section{Quantification reaction}

The final concentrations of the reaction components were as follows: $100 \mathrm{mM}$ Tris- $\mathrm{HCl}$ ( $\mathrm{pH} 7.8$ ), $30 \mathrm{mM} \mathrm{MgCl}_{2}, 0.1 \mathrm{mg} / \mathrm{mL}$ BSA, $200 \mathrm{nM}$ ROX (5-carboxy-X-rhodamine; Invitrogen), $500 \mathrm{nM}$ DL-probe (Sigma-Aldrich Japan), $0.5 \mathrm{U} / \mu \mathrm{L} N b . B b v C$ I (New England Biolabs), 10 (except Fig. 3B) or 100 nM (Fig. 3B) LDNA (quick column grade; GeneDesign), and various concentrations of target (for both DNA and RNA, quick column grade; GeneDesign). For the results shown in Figures 2-5, NBFB_13 was used as the DL-probe, and the other cases were listed in Table 2. All sequences of oligo-DNA and RNA, such as DL-probe, L-DNA, and targets, are shown in Table 1 . We used ribonucleic acid from yeast (Wako) as cellular RNA, and ribonuclease (DNase-free) glycerol solution (Nippon Gene) as RNase A. The reaction mixtures 
$(20 \mu \mathrm{L})$ were monitored at $37^{\circ} \mathrm{C}$ for $30 \mathrm{~min}$ at 15 -sec intervals using an Mx3005 QPCR System (Stratagene). The ratio of the value of fluorescence emission at $516 \mathrm{~nm}$ (excitation at $492 \mathrm{~nm}, 6-\mathrm{FAM}$ fluorescence) to the average value of that at $610 \mathrm{~nm}$ (excitation at $585 \mathrm{~nm}$, ROX fluorescence) for 10-30 min was used as the signal intensity. This correction, dividing by ROX fluorescence, is not necessary for the L-assay itself, but is normally adopted for normalization of the fluorescence intensity differences among tubes when using the Mx3005 QPCR System (and also for other QPCR instruments), which reduces the Cv by $1 \%$ in the L-assay. The signal intensity was converted into the concentration of 6-FAM by linear transformation, because the signals were proportional to the concentration of 6-FAM (data not shown).

\section{Analysis}

The slopes of the fluorescence increase were determined by leastsquares linear regression using the data for 10-30 min shown in Figures $2 \mathrm{~B}, 3 \mathrm{~A}, 3 \mathrm{C}$, and 4 , and in Table 2, and for 5-10 $\mathrm{min}$ in Figure $3 \mathrm{~B}$. The slopes to estimate the target RNA concentration at each time point in Figure 5B were determined by least-squares linear regression using the data $0.5 \mathrm{~min}$ before and after each time point (total of $1 \mathrm{~min}$ ). The secondary structure of the L-DNA was predicted using the software mfold (http://www.bioinfo.rpi.edu/ applications/mfold/) (Mathews et al. 1999; Zuker et al. 1999).

\section{ACKNOWLEDGMENTS}

We thank Drs. Masahiro Takinoue and Daisuke Kiga for fruitful discussion, and Dr. Michael Zuker for mfold. We are also grateful to Drs. Toshio Yanagida, Kotaro Mori, Yasufumi Shima, and Toshihiro Nakashima for helpful discussion. This research was partially conducted in Open Laboratories for Advanced Bioscience and Biotechnology (OLABB), Osaka University, and was supported by "The 21st Century Center of Excellence Program" and "Special Coordination Funds for Promoting Science and Technology: Yuragi Project" of the Ministry of Education, Culture, Sports, Science, and Technology, Japan.

Received August 2, 2007; accepted December 12, 2007.

\section{REFERENCES}

Allawi, H.T., Dahlberg, J.E., Olson, S., Lund, E., Olson, M., Ma, W.P., Takova, T., Neri, B.P., and Lyamichev, V.I. 2004. Quantitation of microRNAs using a modified Invader assay. RNA 10: 11531161.

Bellamy, S.R., Milsom, S.E., Scott, D.J., Daniels, L.E., Wilson, G.G., and Halford, S.E. 2005. Cleavage of individual DNA strands by the different subunits of the heterodimeric restriction endonuclease BbvCI. J. Mol. Biol. 348: 641-653.

Berezikov, E., Cuppen, E., and Plasterk, R.H. 2006. Approaches to microRNA discovery. Nat. Genet. (Suppl.) 38: S2-S7.

Bird, I.M. 1998. Size separation and quantification of mRNA by northern analysis. Methods Mol. Biol. 105: 325-336.

Chen, C., Ridzon, D.A., Broomer, A.J., Zhou, Z., Lee, D.H., Nguyen, J.T., Barbisin, M., Xu, N.L., Mahuvakar, V.R., Andersen, M.R., et al. 2005. Real-time quantification of microRNAs by stem-loop RT-PCR. Nucleic Acids Res. 33: e179. doi: 10.1093/nar/gnil78.
Cherry, J.R., Lamsa, M.H., Schneider, P., Vind, J., Svendsen, A., Jones, A., and Pedersen, A.H. 1999. Directed evolution of a fungal peroxidase. Nat. Biotechnol. 17: 379-384.

Collins, M.L., Irvine, B., Tyner, D., Fine, E., Zayati, C., Chang, C., Horn, T., Ahle, D., Detmer, J., Shen, L.P., et al. 1997. A branched DNA signal amplification assay for quantification of nucleic acid targets below 100 molecules/ml. Nucleic Acids Res. 25: 2979-2984. doi: 10.1093/nar/25.15.2979.

delCardayre, S.B. and Raines, R.T. 1994. Structural determinants of enzymic processivity. Biochemistry 33: 6031-6037.

Eis, P.S., Olson, M.C., Takova, T., Curtis, M.L., Olson, S.M., Vener, T.I., Ip, H.S., Vedvik, K.L., Bartholomay, C.T., Allawi, H.T., et al. 2001. An invasive cleavage assay for direct quantitation of specific RNAs. Nat. Biotechnol. 19: 673-676.

Fersht, A. 1999. Structure and mechanism in protein science: A guide to enzyme catalysis and protein folding. W.H. Freeman, New York.

Hannon, G.J. 2002. RNA interference. Nature 418: 244-251.

Heiter, D.F., Lunnen, K.D., and Wilson, G.G. 2005. Site-specific DNA-nicking mutants of the heterodimeric restriction endonuclease R.BbvCI. J. Mol. Biol. 348: 631-640.

Hosoda, K., Matsuura, T., Kita, H., Ichihashi, N., Tsukada, K., and Yomo, T. 2007. Kinetic analysis of the entire RNA amplification process by $\mathrm{q} \beta$ replicase. J. Biol. Chem. 282: 15516-15527.

Johansson, M.K., Fidder, H., Dick, D., and Cook, R.M. 2002. Intramolecular dimers: A new strategy to fluorescence quenching in dual-labeled oligonucleotide probes. J. Am. Chem. Soc. 124: 69506956.

Jonstrup, S.P., Koch, J., and Kjems, J. 2006. A microRNA detection system based on padlock probes and rolling circle amplification. RNA 12: 1747-1752.

Kean, J.M., Cushman, C.D., Kang, H., Leonard, T.E., and Miller, P.S. 1994. Interactions of oligonucleotide analogs containing methylphosphonate internucleotide linkages and 2'-O-methylribonucleosides. Nucleic Acids Res. 22: 4497-4503. doi: 10.1093/nar/ 22.21.4497.

Langowski, J., Pingoud, A., Goppelt, M., and Maass, G. 1980. Inhibition of Eco RI action by polynucleotides. A characterization of the nonspecific binding of the enzyme to DNA. Nucleic Acids Res. 8: 4727-4736. doi: 10.1093/nar/8.20.4727.

Lim, L.P., Lau, N.C., Weinstein, E.G., Abdelhakim, A., Yekta, S., Rhoades, M.W., Burge, C.B., and Bartel, D.P. 2003. The microRNAs of Caenorhabditis elegans. Genes \& Dev. 17: 991-1008.

MacDougall, D. and Crummett, W.B. 1980. Guidelines for data acquisition and data quality evaluation in environmental chemistry. Anal. Chem. 52: 2242-2249.

Mahony, J.B., Song, X., Chong, S., Faught, M., Salonga, T., and Kapala, J. 2001. Evaluation of the NucliSens Basic Kit for detection of Chlamydia trachomatis and Neisseria gonorrhoeae in genital tract specimens using nucleic acid sequence-based amplification of $16 \mathrm{~S}$ rRNA. J. Clin. Microbiol. 39: 1429-1435.

Maroney, P.A., Yu, Y., Fisher, J., and Nilsen, T.W. 2006. Evidence that microRNAs are associated with translating messenger RNAs in human cells. Nat. Struct. Mol. Biol. 13: 1102-1107.

Marras, S.A., Gold, B., Kramer, F.R., Smith, I., and Tyagi, S. 2004. Real-time measurement of in vitro transcription. Nucleic Acids Res. 32: e72. doi: 10.1093/nar/gnh068.

Marras, S.A., Tyagi, S., and Kramer, F.R. 2006. Real-time assays with molecular beacons and other fluorescent nucleic acid hybridization probes. Clin. Chim. Acta 363: 48-60.

Mathews, D.H., Sabina, J., Zuker, M., and Turner, D.H. 1999. Expanded sequence dependence of thermodynamic parameters improves prediction of RNA secondary structure. J. Mol. Biol. 288: 911-940.

Mothershed, E.A. and Whitney, A.M. 2006. Nucleic acid-based methods for the detection of bacterial pathogens: Present and future considerations for the clinical laboratory. Clin. Chim. Acta 363: 206-220.

Rondelez, Y., Tresset, G., Tabata, K.V., Arata, H., Fujita, H., Takeuchi, S., and Noji, H. 2005. Microfabricated arrays of 


\section{Hosoda et al.}

femtoliter chambers allow single molecule enzymology. Nat. Biotechnol. 23: 361-365.

Sambrook, J. and Russell, D.W. 2001. Molecular cloning: A laboratory manual. Cold Spring Harbor Laboratory Press, Cold Spring Harbor, N.Y.

Tanke, H.J., Dirks, R.W., and Raap, T. 2005. FISH and immunocytochemistry: Towards visualising single target molecules in living cells. Curr. Opin. Biotechnol. 16: 49-54.

Tyagi, S. and Kramer, F.R. 1996. Molecular beacons: Probes that fluoresce upon hybridization. Nat. Biotechnol. 14: 303-308.

Valoczi, A., Hornyik, C., Varga, N., Burgyan, J., Kauppinen, S., and Havelda, Z. 2004. Sensitive and specific detection of microRNAs by northern blot analysis using LNA-modified oligonucleotide probes. Nucleic Acids Res. 32: e175. doi: 10.1093/nar/gnh171.

Wheeler, D.B., Carpenter, A.E., and Sabatini, D.M. 2005. Cell microarrays and RNA interference chip away at gene function. Nat. Genet. (Suppl.) 37: S25-S30.
Xu, Y., Lunnen, K.D., and Kong, H. 2001. Engineering a nicking endonuclease N.AlwI by domain swapping. Proc. Natl. Acad. Sci. 98: 12990-12995.

Yam, W.C., Cheng, V.C., Hui, W.T., Wang, L.N., Seto, W.H., and Yuen, K.Y. 2004. Direct detection of Mycobacterium tuberculosis in clinical specimens using single-tube biotinylated nested polymerase chain reaction-enzyme linked immunoassay (PCR-ELISA). Diagn. Microbiol. Infect. Dis. 48: 271275 .

Zheng, Y. and Roberts, R.J. 2007. Selection of restriction endonucleases using artificial cells. Nucleic Acids Res. 35: e83. doi: 10.1093/ nar/gkm410.

Zuker, M., Mathews, D.H., and Turner, D.H. 1999. Algorithms and thermodynamics for RNA secondary structure prediction: A practical guide. In RNA biochemistry and biotechnology (eds. J. Barciszewski and B.F.C. Clark), pp. 11-43, NATO ASI Series. Kluwer Academic Publishers, Boston, MA. 

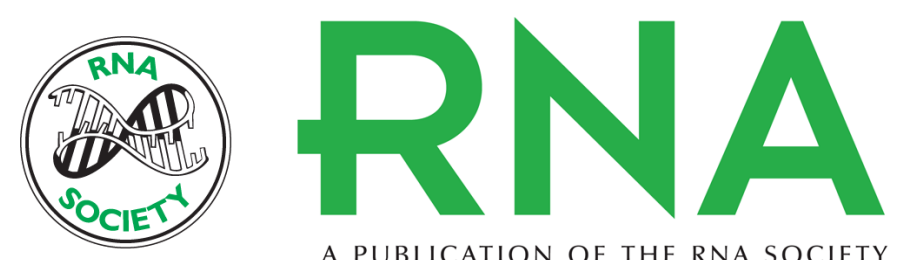

A PUBLICATION OF THE RNA SOCIETY

\section{A novel sequence-specific RNA quantification method using nicking endonuclease, dual-labeled fluorescent DNA probe, and conformation-interchangeable oligo-DNA}

Kazufumi Hosoda, Tomoaki Matsuura, Hiroshi Kita, et al.

RNA 2008 14: 584-592

References This article cites 32 articles, 6 of which can be accessed free at:

http://rnajournal.cshlp.org/content/14/3/584.full.html\#ref-list-1

License

Email Alerting Receive free email alerts when new articles cite this article - sign up in the box at the

Service top right corner of the article or click here.

To subscribe to $R N A$ go to:

http://rnajournal.cshlp.org/subscriptions 